\title{
TRADUÇÃO, CAPITALISMO, PSICANÁLISE
}

\author{
Nils Goran Skare \\ Tradutor Independente \\ nils.skare@gmail.com
}

\begin{abstract}
Resumo: Este artigo defende que o discurso do tradutor é o inverso do discurso do capitalista. Apresentamos a teoria dos discursos do psicanalista Jacques Lacan: o discurso do mestre, do universitário, da histérica e do analista, bem como do capitalista. Desenvolvemos as características do tradutor e sua ética do Real, e apresentamos formalmente seu discurso. Opomos os discursos do tradutor e o do capitalista. Concluímos que o tradutor pode questionar o discurso hegemônico.
\end{abstract}

Palavras-chave: Tradução. Capitalismo. Psicanálise. Lacan. Discurso.

\section{TRANSLATION, CAPITALISM, PSYCHOANALYSIS}

Abstract: This article defends that the discourse of the translator is the inverse of the discourse of the capitalist. We present the theory of discourses of the psychoanalist Jacques Lacan: the discourse of the master, of the university, of the hysteric and of the analyst, as well as the capitalist. We develop the characteristics of the translator and his ethics of the Real, and we formally present his discourse. We oppose the discourses of the translator and of the capitalist. We conclude that the translator can question the hegemonic discourse.

Keywords: Translation. Capitalism. Psychoanalysis. Lacan. Discourse.

\section{Introdução}

Nunca se traduziu tão pouco quanto hoje em dia. Essa afirmação inicial parece um absurdo, certamente. Bastaria verificar o 
aumento na oferta de cursos de língua estrangeira e concluiríamos que a tradução de algum modo se tornou mais "parte do dia-a-dia", um pouco à moda do "acesso à informação" que se tornaria maior graças à presença maciça de televisores e computadores em todos os cantos.

Mas, curiosamente, o fato é que parece que em nenhum dos muitos casos que costumam ser citados como exemplos do aumento do papel do tradutor na sociedade há qualquer menção a uma relação de/da verdade entre sujeito e outro. Pelo contrário, a própria ideia de verdade anda desacreditada. Tudo não passaria de jogos textuais ou ficções construídas entre poderes e saberes. Os sofistas, contra os quais a filosofia se opõe por definição, são esses para os quais:

\section{(...) a oposição fundamental não é entre verdade e erro (...), mas entre palavra e silêncio, entre o que pode ser dito e o que é impossível de dizer. Ou entre os enunciados providos de sentido e os que são desprovidos ${ }^{1}$.}

Parte do propósito deste artigo é jogar luz sobre essa contradição que colocamos sinteticamente no princípio de nosso raciocínio e ajudar a explicar qual é a especificidade da existência (política) do tradutor. Quando se aborda a relação entre tradução e política no contexto acadêmico e da pesquisa científica (esferas que compõem um discurso, como veremos), há duas perspectivas que vêm à mente.

- Primeiramente há uma imagem a respeito do conteúdo dessa relação. Um tradutor que traduz o Mein Kampf está fazendo uma declaração política, vai sem dizer, pela simples natureza do que o texto contém.

- Em segundo lugar há uma imagem que diz respeito à for$m a$ dessa relação. Um exemplo pitoresco poderia ser o do tradutor de orientação conservadora que abranda e atenua passagens picantes de um autor libertino. 
O presente estudo ao redor da tradução e da política não será nem a respeito do conteúdo nem a respeito da forma dessa relação: será a respeito da estrutura do que chamaremos de discurso do tradutor, um discurso inscrito no universo do poder entre os seres humanos.

Somos todos seres da linguagem e o tradutor não é exceção. Assim, ele compõe um discurso (que identificaremos ao longo deste artigo) e ele existe num mundo de outros discursos. Lançar luz sobre a existência discursiva humana (uma tarefa por si só bastante ambiciosa) será um esforço que realizaremos com o auxílio da teoria psicanalítica (de Jacques Lacan). É a partir daí que poderemos traçar o discurso do tradutor. Nesse movimento, constataremos que o tradutor está em contradição com o capitalista.

\section{A teoria do discurso de Jacques Lacan}

Antes de abordarmos a teoria dos discursos de Jacques Lacan (1901-1981), será oportuno deixarmos claro do que não estamos tratando.

- Não estamos lidando com um campo teórico de comunicação e de informação, emergente nas últimas décadas em áreas que vão da informática à genética, que postulam e almejam um comunicação "livre de ruídos".

- Tampouco estamos falando do que se convencionou chamar de "análise de discurso", cujo nome inescapável é certamente o do filósofo francês Michel Foucault. Na análise do discurso de inspiração foucaultiana, o interesse reside na articulação entre o saber e o poder em cada um desses discursos.

A teoria dos discursos de origem psicanalítica de Jacques Lacan é bastante distinta desses dois paradigmas. 
Ao contrário do primeiro, Lacan compreende que a comunicação é sempre imperfeita. A linguagem é cortada pelo desejo. Em certa medida nós falamos porque nossa comunicação é forçosamente imperfeita.

Ao contrário do paradigma foucaultiano, Lacan não se atém ao conteúdo do discurso, mas à sua forma. Em Foucault há uma genealogia dos discursos, em Lacan há uma taxonomia dos discursos.

$\mathrm{O}$ discurso com Lacan é contemplado em seu aspecto relacional passível de formalização. Essa formalização é possível no algoritmo discursivo lacaniano porque ele envolve duas dimensões: posições e elementos.

São quatro as posições discursivas para Jacques Lacan. Inicialmente há um agente e há um outro. O agente se comunica com o outro. Dessa comunicação resulta um produto, que é ao mesmo tempo um núcleo irredutível que o discurso em questão não consegue assimilar. Mas o pensador francês introduz ainda uma quarta posição - e essa é a inflexão propriamente psicanalítica dessa teoria -, uma nova posição que é de fato a primordial; essa é a posição da verdade.

O agente é o mecanismo e a verdade é o seu motor (inconsciente). Levi Bryant, que enriquecerá a teoria do discurso lacaniana no âmbito deste estudo, explora essa posição fundamental da seguinte forma:

\begin{abstract}
A posição da verdade é portanto o agente real do discurso. É simultaneamente o que o discurso tem que velar ou esconder, o que o discurso tem que excluir para funcionar, para ao mesmo tempo ser o que leva adiante o discurso ou que funciona como o "motor" do discurso ${ }^{2}$.
\end{abstract}

Além disso, entre o agente e o outro há uma impossibilidade; entre o produto e a verdade há uma impotência. O agente é levado a comunicar o que sua verdade o força e essa verdade não pode ser completamente verbalizada, (pois uma comunicação perfeita com 
palavras é impossível); se fosse possível ao agente verbalizar total, clara e perfeitamente seu desejo ao outro, o produto seria apropriado (mas isso também é impossível), de modo que o produto comunicacional jamais se enquadra na sua verdade.

Os elementos são representados por quatro matemas: $\$, \mathrm{~S}_{1}, \mathrm{~S}_{2}$ e $a$. Estes representam, nessa ordem, o sujeito, o significante-mestre, a cadeia significante e o objet petit $a$, ou objeto pequeno a.

Primeiramente o sujeito: há uma diferença entre o ego e o sujeito (que retomaremos depois). O ego pertence ao reino do imaginário, ao passo que o sujeito está inscrito no simbólico. O imaginário diz respeito às relações de identificação entre os indivíduos. O imaginário pode ser bem compreendido no deadlock entre a criança e o pai, que vai se resolver no campo da linguagem e da Lei, onde há as relações de reconhecimento. O Simbólico é esse espaço em relação ao qual estamos tentando sempre situar nosso desejo, regidos pela Lei e cortados pela linguagem. O sujeito sofre uma clivagem (Spaltung) entre consciente e inconsciente em virtude da linguagem. É assim que Lacan grafa o sujeito como \$, com um corte.

$\mathrm{O}$ segundo termo de nossa série é $\mathrm{S}_{1}$, o significante-mestre. Ele é um pedaço de nonsense materializado. Um exemplo: no conto de horror Berenice, de Edgar Allan Poe, o narrador Egeu, dotado do que chama de monomania, tenta descrever os dentes de sua futura esposa:

O bater de uma porta me perturbou e, olhando para cima, vi que minha prima havia deixado o recinto. Mas do encerro confuso do meu cérebro, não tinha, ai de mim! partido e não seria expulso o espectro da alvura e visagem dos dentes. (...) Eu os via agora melhor do que os vira então. Os dentes! - os dentes! - eles estavam aqui e lá, em todos os lados, à minha frente espalhados; longos, finos, e brancos em excesso, com os pálidos lábios contorcendo-se ao redor, assim qual no exato momento de sua primeira terrível vertigem ${ }^{3}$. 
Essa "vertigem" no sujeito é fruto da irrupção traumática dos dentes, do Real. O Real existe antes e além da linguagem, escapa à simbolização, não pode ser posto em palavras - e morde.

Os significantes se agrupam em cadeias semióticas $\left(\mathrm{S}_{2}\right)$. Eles são a menor unidade da linguagem para Lacan. É sempre possível acrescentar um novo significante para $S_{2}$, sem fim, tal qual o desejo. Podemos agora enriquecer nossa noção de significante-mestre articulando-a à cadeia-significante: $S_{1}$ "comanda" $S_{2}$. "(...) um significante (...) representa o sujeito para todos os outros significantes."

Resta então falar sobre o elusivo objet petit $a$, o objeto pequeno a, grafado $a$. Em termos bastante simples, quando desejamos alguma coisa é porque algo nos falta e Lacan grafa essa falta sob a forma de uma "positividade". O objet petit a também está ligado ao afeto da angústia, o que exploraremos posteriormente. No momento, contudo, podemos elaborar os discursos fundamentais propostos por Lacan. Cada discurso é formado colocando os elementos nas posições do algoritmo e "girando" os elementos.

\section{Discurso do Mestre}

Podemos ler uma série de atributos. Primeiro, no lugar do agente está o significante-mestre, que é nonsense, isto é, este é um discurso que deve ser obedecido "porque sim". Ele é arbitrário. Ao mesmo tempo, esse discurso esconde algo (\$), em outras palavras, ele tenta ocultar o fato de que é castrado, de que é dividido, de que sofre a Spaltung da linguagem. É preciso ressaltar que, segundo Lacan, o discurso do mestre está em declínio, pelo menos no Ocidente.

\section{Discurso do Universitário}

Aqui é o know-how que está na posição do agente. "Esse discurso é o lugar onde todas as formas de complexidade e ambigüidades são 
mapeadas no domínio do conhecimento." 5 Ao contrário do discurso do mestre, que é do seu jeito "porque sim", o discurso do universitário tem uma infinidade de "porquês" $\left(S_{1}\right)$ para se justificar. Nada é grande demais ou pequeno demais para o universitário e suas explicações. O discurso do universitário é o discurso da burocracia. Vale notar que Lacan identifica um enorme aumento nesse discurso na contemporaneidade, é o próprio discurso da tecnocracia.

\section{Discurso da Histérica}

A histérica (uma mulher ou um homem), se distingue dos outros discursos por ser propriamente o discurso de um sujeito. Ela busca, dirige-se, interpela o mestre para saber sua própria verdade - a verdade do desejo. O discurso da histérica é um discurso que gera saber $\left(\mathrm{S}_{2}\right)$, de todos os tipos. É por isso que Lacan equaciona o discurso da histérica (e não da universidade) ao discurso da ciência. A verdadeira ciência não parte de um conhecimento pronto, mas de um sujeito que se percebe incompleto.

\section{Discurso do Analista}

No discurso do analista é justamente o objeto-causa do desejo que está na posição de agente. Ele se dirige a um sujeito para produzir novas verdades, que permitirão ao outro encontrar novas coordenadas psíquicas. Ao mesmo tempo, o analista é um sujeito-suposto-saber $\left(\mathrm{S}_{2}\right)$, isto é, o analisando acredita que o analista sabe a razão de ser de seu sintoma. Freud descobriu o discurso do analista simplesmente deixando o sintoma falar, simplesmente ficando em silêncio e ouvindo.

Esses são os quatro discursos fundamentais estabelecidos por Jacques Lacan no Seminário XVII - o avesso da psicanálise ${ }^{6}$. Eles formam um "universo do discurso" (para usar uma noção de Levi 
Bryant). Em 1972 Lacan falará de uma espécie de dialeto: o discurso do capitalista (que Levi Bryant classifica dentro de um novo universo do discurso).

\section{Discurso do Capitalista}

A formalização lacaniana deve ser entendida em dois sentidos: no paradigma da produção e no paradigma do consumo, que já exploramos em outro espaço.

Na produção: o trabalhador (\$) se dirige aos meios de produção $\left(\mathrm{S}_{2}\right)$ e com eles gera mercadorias $(a)$. Elas são apropriadas pelos donos da empresa ou pelos acionistas $\left(\mathrm{S}_{1}\right)$; mas essa apropriação é imperfeita, significando que o capital precisa ser utilizado novamente nesse processo para incrementar a eficiência e para vencer a competição. É um círculo vicioso.

No consumo: agora o agente é o consumidor, ele tem a "liberdade" de desejar os bens infinitos do sistema capitalista de produção. Contudo, nenhuma mercadoria pode satisfazer um desejo, gerando insatisfação $(a)$; a partir do momento em que a mercadoria sai da vitrine, ela perde aquele "toque mágico" que a fazia objeto do desejo do Outro, e se revela em sua pobreza real. Mas assim ludibriado o consumidor é levado a querer satisfazer algo em sua posição de verdade $\left(\mathrm{S}_{1}\right)$ que deve ser entendido como o superego.

Aqui é importante uma nota especial sobre o (cruel) papel do superego no capitalismo. O senso comum acredita que o superego seria uma coisa que obriga a pessoa a fazer algo. Isso tinha algum fundamento, pelo menos até a primeira metade do século XX, e gerou uma série de críticos "anti-repressivos" (Reich, Fromm). Mas a verdade é que o imperativo do superego é: goza! O superego é um aparelho que obriga o indivíduo não tanto a fazer algo, mas a gostar do que ele tem que fazer ${ }^{7}$. Levado pela propaganda o consumidor deseja o produto "x", que no entanto sempre decepciona e frustra; mas o superego comanda o sujeito a gozar isso e, ao se 
obedecer à injunção do superego, gera-se mais um círculo vicioso, transformando-se o resultado final em culpa. O capitalismo é uma imensa máquina de transformação de angústia em culpa. Expandiremos esse ponto posteriormente.

\section{O discurso do tradutor}

A tradução é, também ela, um discurso. Se traduzo um viajante estrangeiro para meus amigos monoglotas, por exemplo, estou inscrito numa relação discursiva. Teremos que determinar quem é o outro, quem é esse a quem o tradutor se dirige. Para isso vamos fazer um aparente desvio.

A ética é grosso modo a relação que estabelecemos uns com os outros.

Sob o recorte lacaniano adotado aqui, há três maneiras de se conceber uma ética: uma ética imaginária, uma ética simbólica e uma ética real.

- A ética imaginária é aquela que tenta se construir com base no nosso relacionamento com o outro. A injunção clássica da ética imaginária é: "faça ao outro o que gostaria que ele fizesse a você”.

- A ética simbólica é aquela que procura se fundamentar sobre a pertença a algum Outro que garantiria os direitos de seus membros. Em última instância, esse grupo de pertencimento poderia se estender a toda a espécie humana.

- A ética do Real, por fim, é aquela que existe apenas sob forma negativa, que nos diz o que não devemos fazer.

Defendemos que a ética do Real é a ética do tradutor. Esse ponto por si só exigiria um extenso estudo à parte; mas mesmo aceitando 
essa posição temporariamente for the sake of the argument, o fato é que na verdade não há nele nada de assombroso. Para esclarecer nossa posição vamos parafrasear a título de ilustração uma história selecionada por Žižek a partir de texto de Patricia Highsmith.

Christopher era casado com Penelope; levavam uma vida infeliz. O único refúgio na vida de Penelope era seu hobby de empalhar seus animais de estimação. Ao longo dos anos, ela organizou um museu com esses bichos nos fundos da casa e acabou por chamar a atenção dos jornalistas. Penelope conversou a esse respeito com Christopher, mas este viu na ideia da reportagem uma invasão à sua privacidade. Assim, tiveram uma briga violenta. Durante a noite, Christopher decidiu se vingar. Vários anos antes ele tivera uma amante chamada Louise. Christopher fez um boneco de cera em tamanho real de Louise, e o colocou sentado numa cadeira no meio do jardim de Penelope. No dia seguinte, cercada pelos jornalistas, Penelope foi até seu museu de animais empalhados e, ao se deparar com a estátua da ex-amante do marido, sofreu um ataque cardíaco. Foi levada ao hospital mas não sobreviveu. No outro dia Christopher foi encontrado morto, rijo como um boneco, sentado no colo de Louise ${ }^{8}$.

O "museu" com animais empalhados na parte de trás da casa era o que havia de mais importante na vida de Rebeca. Era isso que sustentava a subjetividade dela. Era algo ridículo, grotesco, estúpido até - mas era o que ela tinha de "mais seu". Esse espaço que proporciona nossas coordenadas psíquicas é o que chamamos de fantasia. O jardim de Rebeca era sua fantasia. E Christopher, ao colocar a boneca da ex-amante lá, colocou exatamente o que não poderia estar nesse espaço. Christopher violentou a fantasia de Rebeca. Por mais que a fantasia de uma pessoa seja um pouco ridícula - e todas elas são - é o que essa pessoa tem para permanecer um ser humano. É por isso que a formulação mínima da ética do Real diz: não violente a fantasia do outro.

O livro 1984 de George Orwell ${ }^{9}$ descreve uma sociedade distópica onde o passado é reescrito continuamente de acordo com a di- 
tadura do onipresente Grande Irmão. Winston Smith, o protagonista do romance, é encarregado de alterar um artigo de jornal para que um membro do partido que caiu em desgraça "nunca tenha existido", substituindo o documento original pela "nova verdade". Esse procedimento, se podemos cunhar um termo à moda do newspeak falado pelos habitantes dessa ditadura, poderia ser chamado de destradução. É bastante improvável que um tradutor como esse cujo discurso estamos tentando delimitar pudesse existir no mundo de 1984. É que o tradutor não se dirige a um certo saber $\left(\mathrm{S}_{2}\right)$ que seria preciso pôr em ordem, ou a um sujeito (\$) que seria preciso "pôr nos trilhos" a serviço de um Grande Outro. Ao contrário do que diz o senso comum, o tradutor não está interessado no que um livro ou uma pessoa "querem dizer", mesmo porque, sempre se pode cair na tentação de que o Simbólico saiba o que isso ou aquilo "quer dizer". O tradutor não deve confiar na palavra do "Grande Irmão". Em outras palavras, a certeza do tradutor de que ele não está destraduzindo é seu apego ao Real. O tradutor se dirige ao "dente" que Edgar A. Poe descreve, isto é, ao significante-mestre $\left(\mathrm{S}_{1}\right)$. Podemos chamar isso também de letra. "Nós designamos por letra esse suporte material que o discurso concreto empresta à linguagem." 10 Para ilustrarmos a situação, podemos aludir a uma analogia que já exploramos em outro lugar (o discurso do tradutor é repleto de analogias, por motivos que esperamos esclarecer em breve ${ }^{11}$ ).

Vamos trabalhar a distinção ego e sujeito que nos conduzirá ao produto do discurso do tradutor. Dentro de um avião, há pelo menos três regimes distintos. Em primeiro lugar, há as telas e as revistas com informações sobre segurança no vôo, publicidades, entretenimento para o viajante, bem como todos os instrumentos variados e delicados que medem e orientam a trajetória. Em segundo lugar, há o espaço das pessoas, propriamente dito, com suas interrelações entre os passageiros, que conversam, ou hierarquicamente com os pilotos, comissários e comissárias. Em terceiro lugar, há o lado de fora, o espaço vazio e ilimitado dos ares. Essa nossa imagem divide nitidamente o que Lacan chama de nó bor- 
romeano: Imaginário em primeiro lugar (o reino das imagens), o Simbólico em segundo lugar (o reino da linguagem e da Lei) e o Real em terceiro lugar (o inabarcável, de dentro do qual se talha a realidade onde vive a subjetividade humana). A letra é a unidade material mínima que compõe a literatura. Mas a letra também compõe a linguagem, isto é, o inconsciente é estruturado como linguagem e a letra é realmente formadora da linguagem. A letra é o real do inconsciente. A Letra é aquilo que faz voar.

Mas podemos conceber um simulador de vôo. Ele simularia as três ordens borromeanas perfeitamente: teríamos instrumentos virtuais para consultar e nos orientar, poderíamos trocar comandos com outros membros virtuais da tripulação e seria possível até mesmo olhar para fora da janela e termos a impressão de estarmos no ar. Simuladores de voo existem e são instrumentos úteis na formação de novos pilotos, mas não há nenhum voo duplicado. Numa simulação, a realidade é reduzida à ordem do ego, mas somos sujeitos. Em outras palavras, a tradução produz um sujeito (\$) devido à maneira como se dirige à letra $\left(\mathrm{S}_{1}\right)$ : na impossibilidade de dizer $\mathrm{o}$ "pedacinho do Real", produz o sujeito (falante).

Dissemos previamente que a tradução é um ato de liberdade, ainda que o senso comum o conceba como um ato mecânico. Vamos voltar por um momento ao mundo de 1984. Nele, Winston Smith é preso ao final e é torturado. Smith, deparando-se com a possibilidade de ser atacado por ratos (seu maior pavor), entrega Julia, com quem tinha uma ligação amorosa. O Grande Irmão esvazia seus dominados de toda jouissance antes de matá-los, como nota o psicanalista francês Jacques Siboni, isto é, a vítima morre já não sendo mais um humano. A destradução anda lado a lado com a desumanização.

$\mathrm{O}$ fato é que o ato de traduzir é potencialmente destrutivo. Na medida em que se dirige a $\mathrm{S}_{1}$ e gera um $\$$ como restante, como "sobra" do processo todo, o discurso do tradutor pode bem dar à luz sujeitos inesperados. Não há nada de errado com isso. O perverso seria o contrário, se sempre o $\$$ resultante fosse previsível. Seria, 
nesse caso, desumano. Significaria, também, que não haveria nenhuma jouissance por parte do agente no discurso do tradutor.

$\mathrm{O}$ tradutor em sua forma pura (é isso que estamos delimitando) age em termos de jouissance. O discurso do tradutor envolve um gozo (a) que se dirige ao Real $\left(\mathrm{S}_{1}\right)$, e é a natureza sui generis desse "obscuro objeto do desejo" que pode produzir um sujeito (\$) como tal.

Só nos resta constatar que a verdade, o motor inconsciente desse discurso é o saber. Se há perguntas inconscientes ao tradutor, uma delas certamente é: "como isto se relaciona com aquilo?" (daí o gosto do tradutor pela analogia, pela imagem, pela alegoria). O tradutor gostaria de saber e de se relacionar perfeitamente com os sujeitos, mas a impotência entre a verdade de seu discurso e seu produto (sua contradição fundamental) faz com que nunca saiba $\left(\mathrm{S}_{2}\right)$ quem são esses sujeitos (\$); ao mesmo tempo, isso aumenta tanto a frustração quanto o mistério e charme deles, gerando jouissance (a) no agente. Esse é seu impulso para ir até o original $\left(\mathrm{S}_{1}\right)$, para dirigir-se ao Real e àquilo que ele tem de mais importante.

\section{Discurso do Tradutor}

O discurso do tradutor é o inverso do discurso do capitalista.

\section{4. $O$ tradutor e o capitalista}

No discurso do tradutor, o objeto-causa do desejo $(a)$ se dirigindo ao Real $\left(\mathrm{S}_{1}\right)$ produz um sujeito $(\$)$ que é em alguma medida fonte de jouissance por ser inapreensível pelo saber do tradutor; no discurso do capitalista, sob o paradigma do consumo por exemplo, o consumidor $(\$)$ se dirigindo às mercadorias $\left(\mathrm{S}_{2}\right)$ produz uma satisfação $(a)$ que o superego $\left(\mathrm{S}_{1}\right)$ se encarrega de transformar em culpa. Podemos agora expandir o ponto anterior a respeito da culpa. Ela pode aparecer em pensamentos (conscientes ou inconscien- 
tes), ou mesmo em atos (se fazemos uma coisa para sermos pegos e assim sermos punidos). Mas Lacan é bastante explícito ao afirmar que a culpa surge quando abrimos mão de nossos desejos.

Como vimos, a interpretação lacaniana do superego é bem distinta da concepção pop de uma instância reguladora que simplesmente proíbe; ao contrário, é uma injunção de gozo. É claro que, na sociedade capitalista, o superego está ligado ao impulso incontrolável, ubíquito e inquestionável de comprar. A obediência, sob o capitalismo, de seguir o comando superegoico de gozar (comprar uma televisão de plasma de 40", por exemplo) não é uma quebra da lei, mas é uma traição do desejo.

Isso nos conduz ao que entendemos como o ponto central da ética psicanalítica para Freud e para Lacan, formulada no seguinte programa: Wo es war, soll ich werden. Ali onde o isto (id, inconsciente) era, devo eu vir-a-ser. Só podemos evitar a culpa ao nos tornarmos os sujeitos de nosso desejo. Isso significa também aprender a lidar com a angústia, sempre presente na tradução. $\mathrm{O}$ tradutor precisa saber persistir na angústia, assim como um equilibrista precisa persistir na corda bamba.

O discurso do tradutor abre um espaço onde é possível descobrir ou pelo menos buscar a natureza do desejo de se tornar um sujeito consciente. $\mathrm{O}$ que o tradutor precisa evitar é a tentação de traduzir aquilo que o texto "quer dizer" $\left(\mathrm{S}_{2}\right)$. Ao contrário, ao traduzir a letra (unidade material mínima da linguagem, do inconsciente e um "pedaço do Real"), o tradutor coloca seu eu (ich) precisamente no isto (es) da letra.

Levi Bryant chama a estrutura discursiva que chamamos de "discurso do tradutor" de "discurso da teoria crítica"12, assim como seria possível ligar outros fenômenos a essa estrutura. O nexo entre tradução e crítica é descrito há muito tempo.

$\mathrm{O}$ tradutor pode desinverter o lado do sujeito no discurso do capitalista, que se transforma no discurso do mestre; a partir daí o discurso do mestre pode ser histerizado pelo discurso do analista. Essa é uma formulação importante e compõe, por si só, no nosso 
entendimento, um (esboço de) programa. Digamos que é uma tática discursiva, mas o autor deste artigo reconhece que não tem uma "solução pronta" e definitivamente não acredita em "milagres". A oposição entre o discurso do tradutor e o discurso do capitalista que ora apresentamos serve, pensamos, para mostrar a profundidade do abismo. Não sabemos como cruzá-lo. De qualquer forma, a teoria serve para desfazer nossas ilusões.

\section{Conclusão}

Vimos a natureza da teoria dos discursos de Lacan. Acompanhamos a construção do algoritmo discursivo com quatro posições e quatro elementos. Formamos os quatro discursos fundamentais, esses que compõem o que Levi Bryant chama de "universo da maestria"; vimos também o discurso do capitalista. Formalizamos o discurso do tradutor e notamos que ele é a inversão do discurso do capitalista. Por fim detectamos que, na dialética entre tradutor e capitalista, o capitalista pode retornar ao discurso do mestre e eventualmente ser histerizado.

Em sua fala em Milão, Lacan salienta que o discurso do capitalista possui um caráter de círculo vicioso e que é "loucamente astucioso"; de qualquer forma, está destinado a uma "explosão" (crévaison $)^{13}$.

O discurso do tradutor, um discurso crítico, pode desempenhar um papel importante em termos políticos, isto é, em termos do poder que se exerce numa sociedade. A práxis tradutória é capaz de pôr em xeque o discurso hegemônico dessa sociedade. As táticas para essa estratégia, contudo, não são tão evidentes.

O presente estudo não tem a pretensão de ser um manifesto, mas à guisa de sugestão para debate, queremos levantar, nos limites deste texto, um tópico vital no contexto político do tradutor: a formação de tradutores. $\mathrm{O}$ discurso do capitalista destaca os elementos do mundo, isola-os e os separa, como se fossem absolutos. 
$\mathrm{O}$ tradutor relaciona. E ao propor às pessoas maneiras de pensar (conscientemente) sua relação com a linguagem, com a sociedade e consigo mesmas, o tradutor está desempenhando seu papel político. Quando um tradutor pergunta a alguém, após ouvir uma história, um "causo" ou um problema, "e como você traduz isso?", a "máquina" do tradutor já se põe para funcionar em oposição à "máquina" capitalista (para usar termos de Deleuze). O caso mais evidente é o ensino formal, na universidade, que pode e deve ser objeto de estudos. Como se aprende tradução? A pergunta é profícua; mais do que isso, é fundamental no contexto que descrevemos sobre tradução. Aí está um tópico que, acreditamos, merece um olhar atento do tradutor em seu papel político, uma inflexão fundamental na práxis que delineamos aqui.

Em certo sentido, defendemos a educação pela pesquisa, para tomarmos emprestado uma expressão do pedagogo Pedro Demo, em todos os contextos, formais e informais, nos quais o tradutor se encontra. E a primeira maneira de pesquisar, para o tradutor, é ouvir (como o analista). Sempre é possível convidar o outro a (se) traduzir, formando novos sujeitos (\$). Isso é transformação (política), isso é tradução.

\section{Notas}

1. BADIOU, Alain. Conditions. Paris: Éditions du Seuil, 1992, p. 60.

2. BRYANT, Levi R. "Žižek's New Universe of Discourse: Politics and the Discourse of the Capitalist". In: International Journal of Žižek Studies, vol. 2, no 4, 2008. p. 41. 
3. POE, Edgar A. Sixty-seven Tales. New York: Gramercy Books, 1990. p. 12.

4. EVANS, Dylan. An Introductory Dictionary of Lacanian Psychoanalysis. London: Routledge. 1996. p. 187.

5. LIU, Catherine. "Lacan's Afterlife: Jacques Lacan meets Andy Warhol” In: RABATÉ, Jean-Michel. The Cambridge Companion to Lacan. Cambridge: Cambridge University Press, 2003. p. 254.

6. LACAN, Jacques. O Seminário Livro XVII - O avesso da psicanálise. Rio de Janeiro: Jorge Zahar Editor, 1992. Tradução: Ari Roitman.

7. ŽIŽEK, Slavoj. Enjoy your symptom! London: Routledge, 2008. p. 208.

8. ŽIŽEK, Slavoj. Looking Awry: an introduction to Jacques Lacan through Popular Culture. Cambridge: MIT Press, 1992. p. 154-155.

9. ORWELL, George. 1984. São Paulo: Companhia das Letras, 2009. Tradução: Alexandre Hubner e Heloisa Jahn.

10. LACAN, Jacques. Escritos. São Paulo: Perspectiva, 2011. p. 225. Tradução: Inês Oseki-Depré.

11. Este comentário de Pfaller, à guisa de nota, é bastante interessante no contexto do pensamento analógico e imagético do tradutor: "Aqui descobrimos por que a filosofia materialista não pode viver sem imagens: para nos libertar da catividade imaginária na qual somos mantidos por certas imagens, precisamos de outras imagens, contra-imagens; pois, como Spinoza afirmou, uma coisa só pode ser limitada por outra coisa da mesma natureza." (PFALLER, Robert. "Interpassivity and Misdemeanors: the analysis of ideology and the Žižekian toolbox.” In: International Journal of Žižek Studies, v. 1, n.1. p. 40).

12. BRYANT, Levi R. “Žižek’s New Universe of Discourse: Politics and the Discourse of the Capitalist”. In: International Journal of Žižek Studies, vol. 2, no 4, 2008. p. 37-39. 
13. LACAN, Jacques. Du Discours Psychanalytique. Disponível em: http://espace.freud.pagespro-orange.fr/topos/psycha/psysem/italie.htm Acessado dia 27 de agosto de 2012.

\section{Referências}

BADIOU, Alain. Conditions. Paris: Éditions du Seuil, 1992.

BRYANT, Levi R. “Žižek's New Universe of Discourse: Politics and the Discourse of the Capitalist”. In: International Journal of Žižek Studies, vol. 2, ${ }^{\circ}$ 4, 2008

EVANS, Dylan. An Introductory Dictionary of Lacanian Psychoanalysis. London: Routledge. 1996

LACAN, Jacques. O Seminário Livro XVII - O avesso da psicanálise. Rio de Janeiro: Jorge Zahar Editor, 1992. Tradução: Ari Roitman

. Escritos. São Paulo: Perspectiva, 2011. p. 225. Tradução: Inês Oseki-Depré.

. Du Discours Psychanalytique. Disponível em: http://espace.freud.pagespro-orange.fr/topos/psycha/psysem/italie.htm Acessado dia 27 de agosto de 2012.

LIU, Catherine. "Lacan's Afterlife: Jacques Lacan meets Andy Warhol" In: RABATÉ, Jean-Michel. The Cambridge Companion to Lacan. Cambridge: Cambridge University Press, 2003

ORWELL, George. 1984. São Paulo: Companhia das Letras, 2009. Tradução: Alexandre Hubner e Heloisa Jahn. 
PFALLER, Robert. "Interpassivity and Misdemeanors: the analysis of ideology and the Žižekian toolbox.” In: International Journal of Žižek Studies, v. 1, n.1

POE, Edgar A. Sixty-seven Tales. New York: Gramercy Books, 1990

ŽIŽEK, Slavoj. Enjoy your symptom! London: Routledge, 2008

. Looking Awry: an introduction to Jacques Lacan through Popular Culture. Cambridge: MIT Press, 1992.

Recebido em 05/9/2012

Aceito em 10/12/2012 